\title{
Descoloração redutiva do corante azo RR2 na ausência e presença de mediador redox e aceptor de elétrons nitrato
}

\section{Reductive decolorization of the azo dye RR2 in the absence and presence of redox mediator and the electrons acceptor nitrate}

\author{
Carlos Henrique da Costa Braúna \\ Engenheiro civil. Mestre em Engenharia Civil, área de concentração em Saneamento Ambiental, pela Universidade Federal do Ceará (UFC). Doutorando em \\ Engenharia Civil, área de concentração em Saneamento Ambiental, pela UFC

\begin{abstract}
Suetônio Mota
Engenheiro civil e sanitarista. Doutor em Saúde Ambiental pela Universidade de São Paulo (USP). Professor Titular do Departamento de Engenharia Hidráulica e Ambiental do Centro de Tecnologia da UFC
\end{abstract}

André Bezerra dos Santos

Doutor em Ciências do Meio Ambiente pela Wageningen University, Holanda. Professor adjunto do Departamento de Engenharia Hidráulica e Ambiental UFC

\begin{abstract}
Resumo
A presente investigação teve como objetivo estudar o efeito do nitrato na descoloração de corantes em reatores anaeróbios suplementados ou não com mediadores redox. Dois reatores anaeróbios em paralelo foram operados com tempo de detenção hidráulica (TDH) de dez horas, utilizando-se etanol como cossubstrato. Os resultados provaram que os reatores eram eficientes na remoção de cor, sendo o composto etanol um eficiente doador de elétrons para sustentar a redução do corante azo nos reatores mesofílicos. O mediador redox AQDS aumentou as taxas de redução do corante azo, mas o seu efeito não foi tão marcante comparado aos experimentos realizados anteriormente. Contrariamente às hipóteses levantadas de que a adição de nitrato poderia interferir nas taxas de remoção de cor e propriedades catalíticas do mediador redox, não se verificou nenhum efeito desse composto.
\end{abstract}

Palavras-chave: corante azo; mediadores redox; nitrato; etanol; tratamento anaeróbio.

\begin{abstract}
This paper aimed at evaluating the effect of nitrate on anaerobic azo dye reduction by using mesophilic bioreactors, in the absence and in the presence of redox mediators. Two anaerobic bioreactors were operated in parallel with a hydraulic retention time (HRT) of ten hours; ethanol was used as co-substrate. The results showed that the bioreactors were efficient on dye reduction, and the ethanol showed to be a good electron donor to sustain it. The redox mediator AQDS increased the rates of reductive decolourisation, but its effect was not so remarkable compared to the previous experiments conducted. Contrary to the raised hypothesis that nitrate addition could decrease the colour removal efficiency and catalytic properties of the redox mediators, no effect of nitrate was observed in the bioreactors.
\end{abstract}

Keywords: azo dye; redox mediators; nitrate; ethanol; anaerobic treatment.

\section{Introdução}

Devido ao crescimento da indústria têxtil no Brasil e no mundo verificado nos últimos anos, há um aumento na produção de águas residuárias, o que contribui potencialmente com a degradação do meio ambiente caso alcancem águas superficiais e subterrâneas. Assim, deve-se evitar a chegada de efluentes têxteis sem tratamento no meio ambiente por meio da implementação de Estações de Tratamento de
Esgotos dimensionadas para a remoção de cor, demanda química de oxigênio (DQO), e outros contaminantes presentes.

Uma das principais características desse tipo de efluente é ser altamente colorido, resultado principalmente dos corantes aplicados nas operações de tingimento e que não aderem às fibras (DOS SANTOS; CERVANTES; VAN LIER, 2007, VAN DER ZEE; VILLAVERDE, 2005). Dos diversos corantes empregados na indústria têxtil, merece destaque a classe dos corantes azo, pois representa a maior parcela de

Endereço para correspondência: André Bezerra dos Santos - Campus do Pici, bloco 713 - Pici - 60451-970 - Fortaleza (CE), Brasil - Tel.: (85) 33669490 -

E-mail: andre23@ufc.br

Recebido: 12/8/08 - Aceito: 10/2/09 - Reg. ABES: 123/08 
corantes usados no processo de tingimento (cerca de 70\% em peso) (PEARCE et al, 2006). Por isso, vários estudos de remoção de cor de esgotos contendo essa classe de corantes têm sido realizados em todo o mundo, principalmente visando à inclusão do tratamento biológico de esgotos, por se constituírem como a alternativa de menor custo.

Normalmente a descoloração de corantes azo sob condições anaeróbias, também conhecida como redução do corante azo, procede mais rapidamente quando comparada a condições aeróbias, porque o corante é o único aceptor dos elétrons gerados nos processos oxidativos (DOS SANTOS; CERVANTES; VAN LIER, 2007; VAN DER ZEE; VILLAVERDE, 2005). Sob condições aeróbias, os elétrons gerados são transferidos para o oxigênio devido ao elevado valor do potencial padrão de redução e, consequentemente, não há remoção biológica de cor. Entretanto, os produtos resultantes da quebra redutiva anaeróbia, conhecidos como aminas aromáticas, são normalmente recalcitrantes nessa condição, necessitando de um pós-tratamento para sua completa eliminação (FIELD et al, 2000; DOS SANTOS, 2005). Um roteiro de tratamento que vem sendo investigado é o uso de reatores anaeróbios seguido de reatores aeróbios, sequência na qual as aminas aromáticas geradas no primeiro reator (anaeróbio) podem ser utilizadas como fonte de nitrogênio no segundo reator (aeróbio) (FIELD et al, 1995).

A remoção de cor de corantes em reatores anaeróbios, apesar de possível, ainda constitui um processo lento para muitos corantes recalcitrantes, necessitando assim de elevado tempo de detenção hidráulica (TDH) para que se obtenham boas taxas de descoloração (DOS SANTOS; CERVANTES, VAN LIER, 2007). Visando a aumentar a cinética dessa reação, substâncias com potencial catalítico têm sido investigadas, os chamados mediadores redox, e testadas em concentrações catalíticas, ou seja, em baixíssimas concentrações, na ordem de grandeza de $\mu \mathrm{M}$ (CERVANTES et al, 2001; RAU; KNACKMUSS; STOLZ, 2002; FIELD; BRADY, 2003; DOS SANTOS et al, 2004; DOS SANTOS, 2005).

A literatura registra resultados contraditórios no que diz respeito ao efeito da presença de aceptores alternativos de elétrons, como nitrato e sulfato, na diminuição das taxas de remoção de cor. Por exemplo, Carliell et al (1995) verificaram que a taxa de redução do corante azo Reactive Red 141 sob condições anaeróbias era consideravelmente reduzida na presença de nitrato, sendo que não se observava nenhum efeito na presença do composto sulfato. Contrariamente, Pearce et al (2006) não observaram qualquer efeito do nitrato nas taxas de remoção de cor do corante azo Remazol Black B pelo micro-organismo aeróbio Shewanella espécie J18 143, sendo que a concentração de nitrato era cerca de 800 vezes superior à concentração do corante.

Entretanto, o efeito de aceptores alternativos de elétrons nas reações bioquímicas envolvidas nos processos de remoção de cor sempre foi investigado na ausência de mediadores redox. A presente investigação teve como objetivo estudar o efeito do nitrato na descoloração de corantes em reatores anaeróbios suplementados ou não com mediadores redox.

\section{Metodologia}

\section{Compostos químicos}

Foi usado o corante azo RR2 (Reactive Red 2) como composto modelo para esse estudo. O RR2 (Figura 1) foi testado na forma analítica, sem adicional purificação. Para composto modelo de mediador redox, foi selecionado o composto quinônico antraquinona-2,6-dissulfonado (AQDS) (Figura 2), testado também sem nenhuma purificação (SigmaAldrich, UK). Para os experimentos com nitrato, utilizou-se o composto nitrato de sódio $\left(\mathrm{NaNO}_{3}\right)$.

\section{Experimento em fluxo contínuo}

Todos os experimentos foram realizados no Laboratório de Saneamento (Labosan) do Departamento de Engenharia Hidráulica e Ambiental da Universidade Federal do Ceará (UFC) no período de abril a setembro de 2006.

O lodo inoculado nos reatores era uma mistura de dois lodos anaeróbios: um lodo granular coletado em um reator mesofílico do tipo UASB, o qual tratava águas residuárias de papel (Eerbeek, Países Baixos), sendo o outro um lodo floculento coletado em um reator UASB que tratava esgoto de uma indústria de cerveja de Fortaleza, Brasil, com uma concentração aproximada de sólidos suspensos voláteis (SSV) de $30 \mathrm{~g} / \mathrm{L}$ de reator. O período de aclimatação foi de aproximadamente um mês, realizado em dois reatores anaeróbios de leito expandido (EGSB, Expanded granular sludge blanket) mesofílicos, cada qual com volume útil de 0,53 L: R1 (suplementado com o mediador redox AQDS) e R2 (sem AQDS). Os reatores foram operados com um tempo de detenção hidráulica (TDH) de dez horas e taxa de carga orgânica de $2,5 \mathrm{~kg}$ de DQO $\mathrm{m}^{-3} \mathrm{~d}^{-1}$. A velocidade de fluxo ascensional foi de $4 \mathrm{~m} / \mathrm{h}$, alcançada com auxilio de bombas peristálticas. Um esquema com os reatores usados no experimento é representado na Figura 3.

Após a obtenção de condições estáveis de operação, verificadas por meio de análises de pH e DQO, deu-se início ao experimento em fluxo contínuo, que foi dividido em três etapas principais, conforme mudanças dos parâmetros operacionais. Na primeira etapa, compreendida pelos períodos I, II e III, os reatores receberam corante RR2, a fim de se estudar o processo de remoção de cor de corantes sob condições anaeróbias.

Na segunda fase, compreendida pelos períodos IV, V e VI, o reator R1 foi suplementado com concentrações catalíticas do mediador redox AQDS para que se avaliasse o efeito desse composto nas taxas de descoloração. Por fim, na terceira etapa (períodos VII e VIII), os reatores foram suplementados com o composto nitrato nas concentrações de 3 e $5 \mathrm{mM}$, para que se avaliasse o efeito de aceptores alternativos de elétrons nas taxas de descoloração e propriedades catalíticas do AQDS. 


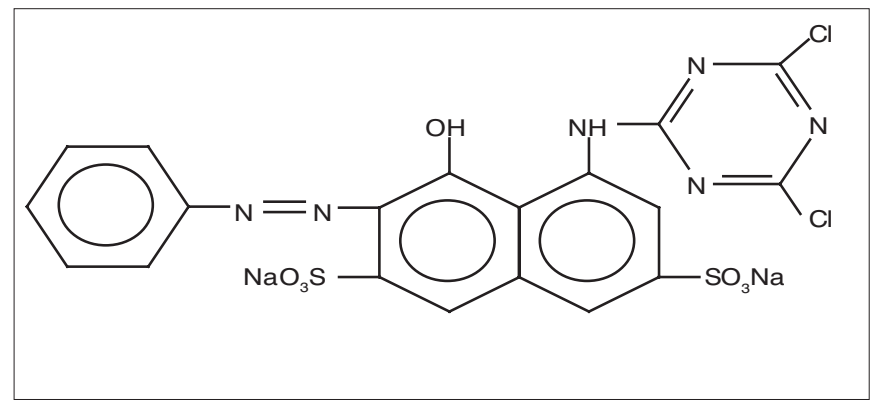

Figura 1 - Estrutura química do corante azo RR2<smiles>O=C1c2ccc(S(=O)(=O)O[Na])cc2C(=O)c2ccc(S(=O)(=O)O)cc21</smiles>

Figura 2 - Estrutura química do mediador redox AQDS

$\mathrm{O}$ meio basal consistiu em macronutrientes (mg/L): $\mathrm{NH}_{4} \mathrm{CL}$ (280), $\mathrm{K}_{2} \mathrm{HPO}_{4}$ (250), $\mathrm{MgSO}_{4} \cdot 7 \mathrm{H}_{2} \mathrm{O}$ (100) e $\mathrm{CaCl}_{2} \cdot 2 \mathrm{H}_{2} \mathrm{O}$ (10) e $1 \mathrm{~mL} / \mathrm{L}$ de solução de elementos traços, a qual continha os seguintes reagentes (mg/L): $\mathrm{H}_{3} \mathrm{BO}_{3}(50), \mathrm{FeCL}_{2} \cdot 4 \mathrm{H}_{2} \mathrm{O}$ (2000), $\mathrm{ZnCl}_{2}$ (50), $\mathrm{MnCL}_{2} \cdot 4 \mathrm{H}_{2} \mathrm{O}$ (500), $\mathrm{CuCl}_{2} \cdot 2 \mathrm{H}_{2} \mathrm{O}$ (38), $\left(\mathrm{NH}_{4}\right)_{6} \mathrm{Mo}_{7} \mathrm{O}_{24} \cdot 4 \mathrm{H}_{2} \mathrm{O}$ (50), $\mathrm{AlCl}_{3} \cdot 6 \mathrm{H}_{2} \mathrm{O}$ (90), $\mathrm{CoCl}_{2} \cdot 6 \mathrm{H}_{2} \mathrm{O}$ (2000), $\mathrm{NiCl}_{2} \cdot 6 \mathrm{H}_{2} \mathrm{O}$ (92), $\mathrm{Na}_{2} \mathrm{SeO}_{3} \cdot 5 \mathrm{H}_{2} \mathrm{O}$ (162), EDTA (1000) e HCl 36\% (1). O meio foi tamponado com 2,5 g/L de bicarbonato de sódio, de forma a manter o $\mathrm{pH}$ próximo a 7 . Os experimentos eram conduzidos em temperatura ambiente, em torno de $28 \pm 2{ }^{\circ} \mathrm{C}$.

\section{Experimento em batelada}

Para o experimento em batelada foram utilizados os mesmos compostos químicos e o mesmo meio basal do experimento em fluxo contínuo. Usou-se uma concentração aproximada de lodo de 0,9 gSSV/L, coletado no reator R2. As garrafas em série eram em borossilicato e possuíam um volume total de $117 \mathrm{~mL}$. Após adição de $50 \mathrm{~mL}$ de meio basal, os recipientes eram selados com borrachas de butil e prendedores de alumínio. Condições anaeróbias foram obtidas pela troca gasosa do headspace das garrafas pela injeção de $\mathrm{N}_{2}: \mathrm{CO}_{2}(70 / 30 \%)$ durante um minuto, sendo adicionados em seguida o cossubstrato (etanol), corante (RR2) e mediador redox (AQDS), de acordo com a Tabela 1.

Todas as configurações foram testadas em duplicata, sendo que o corante azo RR2 e o mediador redox AQDS foram testados nas concentrações de 0,06 mM e $25 \mu \mathrm{M}$, respectivamente. As garrafas 3 e 4 (G3 e G4) foram autoclavadas durante uma hora a uma

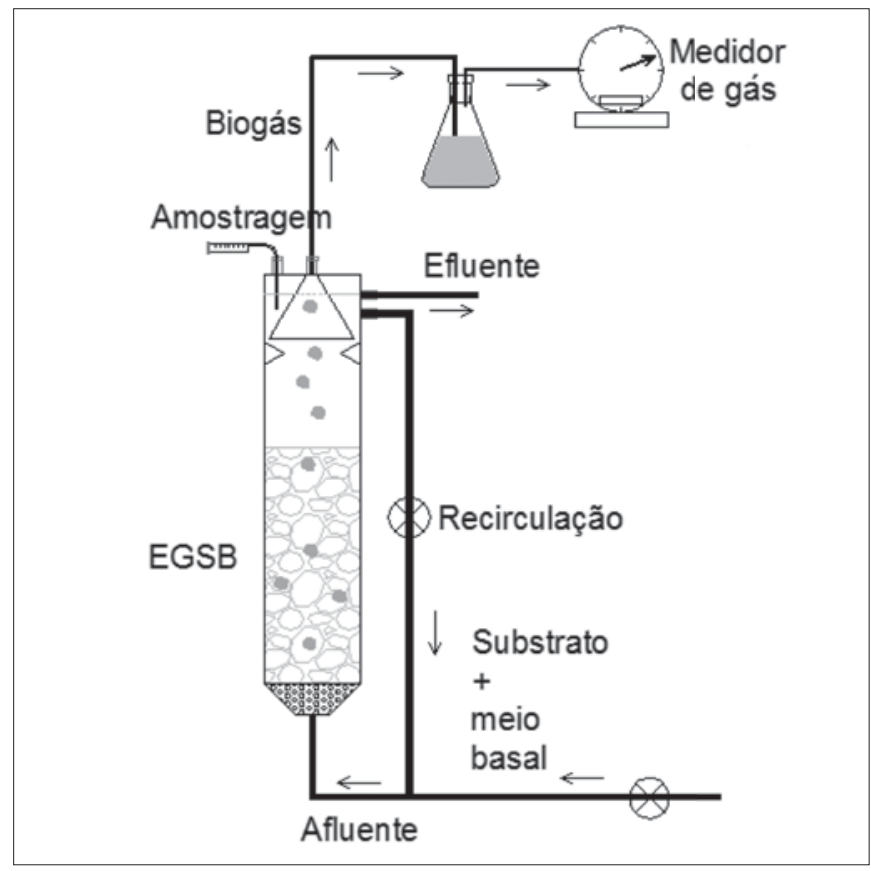

Figura 3 - Esquema dos reatores anaeróbios do tipo EGSB utilizados nos experimentos de fluxo contínuo

Tabela 1 - Configuração das garrafas usadas no experimento em batelada

\begin{tabular}{|c|c|c|c|c|}
\hline Garrafa & $\begin{array}{l}\text { Lodo } \\
\text { (gSSV/L) }\end{array}$ & $\begin{array}{l}\text { Concentração de } \\
\text { etanol (mgDQO/L) }\end{array}$ & $\begin{array}{l}\text { AQDS } \\
(\mu \mathrm{M})\end{array}$ & Comentário \\
\hline 1 e 2 & - & - & - & Controle químico \\
\hline 3 e 4 & 0,9 & - & - & Lodo autoclavado \\
\hline 5 e 6 & 0,9 & - & - & Controle endógeno \\
\hline 7 e 8 & 0,9 & 50 & - & \\
\hline 9 e 10 & 0,9 & 100 & - & \\
\hline 11 e 12 & 0,9 & 500 & - & \\
\hline 13 e 14 & 0,9 & 1.000 & - & \\
\hline 15 e 16 & 0,9 & 100 & 25 & \\
\hline 17 e 18 & 0,9 & 500 & 25 & \\
\hline 19 e 20 & 0,9 & 1.000 & 25 & \\
\hline
\end{tabular}

temperatura de $120^{\circ} \mathrm{C}$ para funcionarem como controle abiótico. Os experimentos eram conduzidos em temperatura ambiente, em torno de $28 \pm 2{ }^{\circ} \mathrm{C}$

\section{Análises}

Foram realizadas análises periódicas de $\mathrm{pH}$, cor, alcalinidade, ácidos graxos voláteis (AGV) e DQO do afluente e efluente dos reatores. As análises de cor foram realizadas em um espectrofotômetro Dr 2500 da marca Hach no comprimento de onda máximo ( $\lambda$ para o RR2 que era $539 \mathrm{nM}$ ). Antes das leituras, as amostras eram diluídas em uma solução de tampão de fosfato e centrifugadas a 13 mil RPM por dez minutos. As demais análises, incluindo AGV e alcalinidade, realizadas por titulação, seguiram as recomendações do Standard methods for the examination of water and wastewater (APHA, 2000). 


\section{Resultados e discussão}

Os resultados obtidos nas várias fases do experimento em relação às remoções de $\mathrm{DQO}$, cor, AGV, pH e alcalinidade nas três fases principais do experimento, são apresentados a seguir.

\section{Investigação após condições estáveis de operação (primeira fase)}

Após obtidas condições estáveis de operação (Período I), adicionou-se o corante RR2 em ambos os reatores na concentração de 0,02 g/L (Período II). Essa concentração foi dobrada no Período III. A Tabela 2 compila os parâmetros operacionais e resultados de eficiência dos reatores R1 e R2 nos três primeiros períodos iniciais da pesquisa. A eficiência de remoção de cor após a obtenção de condições estáveis de operação é apresentada na Figura 4.

Tabela 2 - Dados operacionais do experimento em fluxo contínuo nos três primeiros períodos da pesquisa, sem a presença de AQDS

\begin{tabular}{lccc} 
Período & I & II & III \\
\hline Fim do período (dias) & 35 & 48 & 63 \\
\hline Cossubstrato (gDQO/L) & 1,35 & 1,35 & 1,35 \\
\hline RR2 (g/L) & - & 0,02 & 0,04 \\
\hline Nitrato (mM) & - & - & - \\
$\begin{array}{l}\text { COV cossubstrato } \\
\text { (gDQO/L.dia) }\end{array}$ & 2,5 & 2,5 & 2,5 \\
COV RR2 (gRR2/L.dia) & - & 0,04 & 0,08 \\
$\begin{array}{l}\text { Cossubstrato/corante azo } \\
\text { (gDQO/gRR2) }\end{array}$ & - & 62,5 & 31,25 \\
AQDS ( $\mu$ M) R1 & - & - & - \\
& Eficiência dos reatores & \\
Remoção DQO R1(\%) & $89(9,30)$ & $92(2,97)$ & $87(2,28)$ \\
Remoção DQO R2 (\%) & $83(11,45)$ & $91(4,80)$ & $88(2,19)$ \\
Remoção cor R1 (\%) & - & $80(5,42)$ & $74(8,48)$ \\
Remoção cor R2 (\%) & - & $84(4,16)$ & $69(7,33)$
\end{tabular}

COV: carga orgânica volumétrica.

O desvio padrão é mostrado entre parênteses.

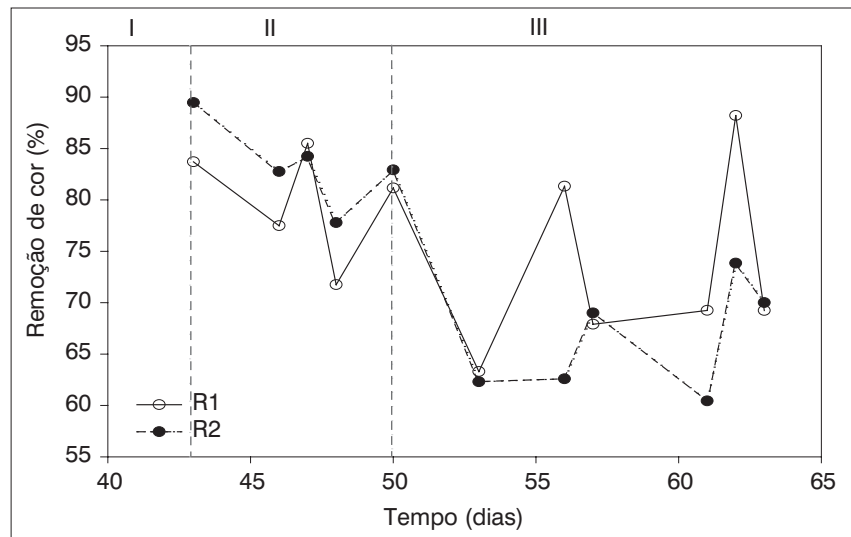

Figura 4 - Eficiência de remoção de cor após a obtenção de condições estáveis de operação
Os resultados mostram claramente que os reatores foram eficientes na redução de cor do corante azo RR2. No período II houve mais de $80 \%$ de remoção de cor do afluente contendo corante para ambos os reatores. O reator $\mathrm{R} 2$ se mostrou pouco melhor do que o R1 no Período II (84 a 80\%). Essas taxas elevadas podem ter sido decorrentes da adsorção inicial de parte do corante na manta de lodo nos primeiros dias de experimento. Após a duplicação da concentração do corante (Período III), houve uma pequena queda na eficiência dos reatores, que se mantiveram com médias similares de redução, $74 \mathrm{e}$ $69 \%$ para R1 e R2, respectivamente.

As eficiências de remoção de cor da presente investigação são melhores do que as obtidas por Dos Santos (2005), ou seja, 56\%, em um reator EGSB operado sob condições mesofílicas com um TDH de dez horas, e COV do corante RR2 igual a 1,25 gRR2/L.dia. No trabalho supracitado, o autor utiliza uma mistura de glicose e ácidos graxos voláteis como doador de elétrons, sendo que no presente trabalho foi utilizado etanol. Ainda em Dos Santos (2005), em experimentos em batelada, é mostrado que etanol é um doador de elétrons mais eficiente para sustentar o processo de remoção de cor quando comparado a uma mistura de glicose/AGV. Uma outra possibilidade pode ser relacionada à baixa concentração de corante utilizada no presente experimento que, juntamente com a alta concentração de biomassa no reator, promoveu uma cinética de ordem zero e, consequentemente, maiores valores de eficiência.

Outros autores atribuem a diminuição da eficiência de remoção de cor em reatores a problemas de toxicidade do corante à biomassa anaeróbia. Por exemplo, Carliell et al (1995) estudaram a toxicidade de elevadas concentrações do corante azo Reactive Red 141 (superiores a $200 \mathrm{mg} / \mathrm{L}$ ) nos micro-organismos anaeróbios, principalmente os metanogênicos. Estudos realizados por Razo-Flores (1997) mostram que corantes azo são muito mais tóxicos à biomassa anaeróbia do que os produtos de sua quebra, as aminas aromáticas. Muitos estudos que relatam inibição do processo de descoloração em relação à concentração do corante utilizaram concentrações muito elevadas de corante, que excedem em muito os valores comumente encontrados no efluente das indústrias têxteis, entre 10 e 250 mg/L (VAN DER ZEE; VILLAVERDE, 2005). Entretanto, devido às baixas concentrações testadas no presente experimento, não se verificou qualquer problema aparente de toxicidade.

\section{Avaliação do efeito do mediador redox nas taxas de remoção de cor}

A segunda etapa da pesquisa foi constituída pela verificação do efeito do mediador redox AQDS nas taxas de remoção de cor e remoção de DQO (Tabela 3).

Assim, o reator Rl foi inoculado com AQDS na concentração inicial de 12,5 $\mu \mathrm{M}$ (Período IV). No período V, dobrou-se novamente a concentração do corante azo RR2, mantendo-se a mesma 
concentração de AQDS do período IV. No Período VI, dobrou-se a concentração de AQDS de maneira a se evidenciar ainda mais o efeito catalisador do mediador redox. O efeito do AQDS nas eficiências de remoção de cor é mostrado na Figura 5.

Após a adição de concentrações catalíticas de AQDS no reator R1, as taxas de descoloração aumentaram imediatamente e permaneceram mais altas que os valores encontrados no reator R2. O máximo efeito do AQDS foi observado durante o primeiro tempo de adição (período IV) no qual um aumento de 1,2 vezes na remoção de cor foi obtido. Entretanto, não se verificou aumento nas taxas de remoção de cor quando a concentração de AQDS foi elevada para $25 \mu \mathrm{M}$ (Período VI).

O efeito do AQDS nas taxas de remoção de cor está de acordo com os experimentos conduzidos por Dos Santos et al (2005), operando dois reatores mesofílicos (sendo um deles suplementado com AQDS) com TDH de dez horas, concentração de RR2 de 0,3 mM e concentração de AQDS de $25 \mu \mathrm{M}$. Foram obtidas diferenças de até 32\% nas taxas de descoloração entre os dois reatores. O autor usou uma razão corante/AQDS de 12 , valor mais alto do que o usado na presente pesquisa $(4,8)$, o que em teoria é contraditório, pois se verifica um maior impacto de AQDS para menores valores da relação corante/AQDS.

Uma possibilidade capaz de explicar as baixas propriedades catalíticas do AQDS é relacionada à baixa concentração testada do corante aliada à alta concentração de biomassa no reator, que pode ter produzido uma cinética de ordem zero, logo mascarando o efeito do AQDS. Uma outra possibilidade pode ser atribuída ao doador primário de elétrons testado, já que Dos Santos (2005) usou uma mistura de glicose e ácidos graxos voláteis, enquanto o etanol foi usado no presente estudo. O último composto tem provado ser um substrato melhor para suprir a redução do corante em comparação à mistura de glicose e AGV (DOS SANTOS, 2005). Logo, o tipo de doador de elétrons também desempenha um importante papel no impacto do AQDS em aumentar as taxas de redução do corante.

Kudlich, Keck e Stolz (1997) obtiveram em batelada taxas de descoloração do corante azo Amaranth proporcionais à concentração do mediador redox AQS na presença do micro-organismo Sphingomonas $s p$ variedade BN6 com glicose como substrato. Contudo, em concentrações acima de 0,6 mM de AQS, não houve aumento nas taxas de descoloração. Em outro experimento, Field e Brady (2003) usaram riboflavina como mediador redox em temperatura mesofílica para a redução do corante azo Mordant Yellow 10 e relataram pequenas variações das taxas de remoção de cor para concentrações de riboflavina maiores do que $0,055 \mathrm{mM}$, o que foi atribuído à cinética de saturação da redução enzimática da riboflavina.

\section{Avaliação do efeito do nitrato nas taxas de remoção de cor}

Na terceira etapa da pesquisa (Tabela 4 e Figura 6) ambos os reatores receberam afluente com nitrato, um suposto receptor preferencial de elétrons em relação ao corante e ao AQDS, nas concentrações de $3 \mathrm{mM}$ (Período VII) e 5mM (Período VIII). Considerando-se a presença do nitrato, as hipóteses levantadas são: 1) nitrato modifica o potencial redox do meio e 2) devido à atividade desnitrificante, há uma competição entre os micro-organismos redutores de corantes e desnitrificantes pelos equivalentes reduzidos disponíveis. Assim, o nitrato poderia interferir nas taxas de remoção de cor e na capacidade do mediador redox funcionar como um catalisador da reação.

Como pode ser observado, nitrato, na concentração de $3 \mathrm{mM}$ (Período VII), não resultou na diminuição das taxas de remoção de cor de ambos os reatores, em que as eficiências médias de remoção de cor mantiveram-se em 83 e $72 \%$ para os reatores R1 e R2, respectivamente. O aumento da concentração de nitrato para $5 \mathrm{mM}$ (Período VIII), novamente, não influenciou nem a cinética de descoloração, nem o impacto do mediador redox AQDS.

Os resultados da presente investigação estão em desacordo com o experimento realizado por Carliell et al (1995) que estudaram a

Tabela 3 - Dados operacionais do experimento em fluxo contínuo na presença do mediador redox AQDS. 0 reator R1 era suplementado com AQDS

\begin{tabular}{|c|c|c|c|}
\hline Período & IV & V & VI \\
\hline Fim do período (dias) & 78 & 92 & 113 \\
\hline Cossubstrato (gDQO/L) & 1,35 & 1,35 & 1,35 \\
\hline RR2 (g/L) & 0,04 & 0,08 & 0,08 \\
\hline Nitrato (mM) & - & - & - \\
\hline $\begin{array}{l}\text { COV cossubstrato } \\
\text { (gDQO/L.dia) }\end{array}$ & 2,5 & 2,5 & 2,5 \\
\hline COV RR2 (gRR2/L.dia) & 0,08 & 0,16 & 0,16 \\
\hline $\begin{array}{l}\text { Cossubstrato/corante azo } \\
\text { (gDQO/gRR2) }\end{array}$ & 31,25 & 15,6 & 15,6 \\
\hline AQDS $(\mu \mathrm{M}) \mathrm{R} 1$ & 12,5 & 12,5 & 25 \\
\hline \multicolumn{4}{|c|}{ Eficiência dos reatores } \\
\hline Remoção DQO R1(\%) & $83(2,91)$ & $81(3,31)$ & $84(6,14)$ \\
\hline Remoção DQO R2 (\%) & $83(1,28)$ & $81(5,67)$ & $82(5,67)$ \\
\hline Remoção cor R1 (\%) & $79(5,41)$ & $83(2,15)$ & $83(2,64)$ \\
\hline Remoção cor R2 (\%) & $66(6,84)$ & $75(2,24)$ & $72(5,50)$ \\
\hline
\end{tabular}

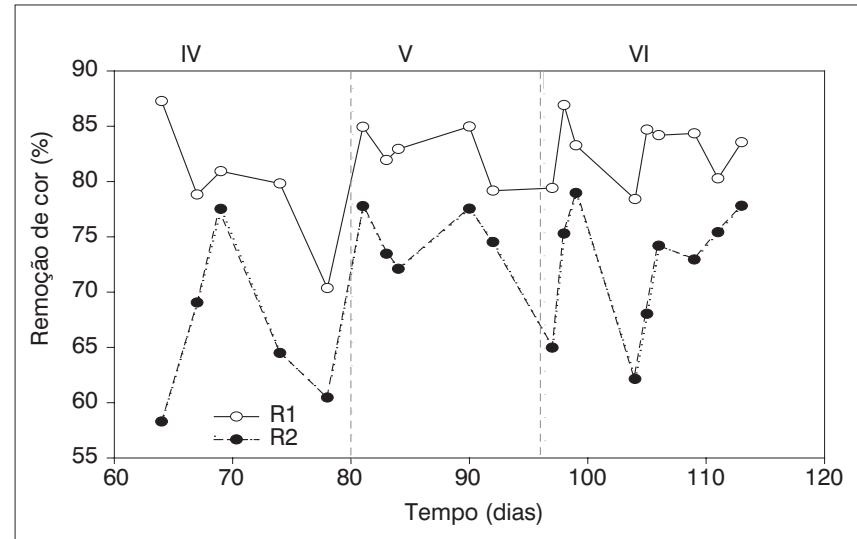

Figura 5 - Eficiência de remoção de cor dos reatores R1 e R2 quando AQDS era introduzido no sistema 
Tabela 4 - Dados operacionais do experimento em fluxo contínuo na presença do mediador redox AQDS. R1 e R2 são reatores suplementados e livres de AQDS respectivamente

\begin{tabular}{lcc|} 
Período & VII & VIII \\
\hline Fim do período (dias) & 134 & 152 \\
\hline Cossubstrato (gDQO/L) & 1,35 & 1,35 \\
RR2 (g/L) & 0,08 & 0,08 \\
Nitrato (mM) & 3 & 5 \\
COV cossubstrato & 2,5 & 2,5 \\
(gDQO/L.dia) & 0,16 & 0,16 \\
COV RR2 (g/L.dia) & 15,6 & 15,6 \\
Cossubstrato/corante azo & 25 & 25 \\
(gDQO/gRR2) & $83(1,98)$ & $79(1,02)$ \\
AQDS ( $\mu$ M) R1 & $87(0,95)$ & $74(6,27)$ \\
& $83(4,12)$ & $83(3,45)$ \\
Remoção DQO R1(\%) & $74(5,04)$ & $71(4,60)$ \\
Remoção DQO R2 (\%) & & \\
Remoção cor R1 (\%) & & \\
Remoção cor R2 (\%) & &
\end{tabular}

COV: carga orgânica volumétrica.

O desvio padrão é mostrado em parêntese.

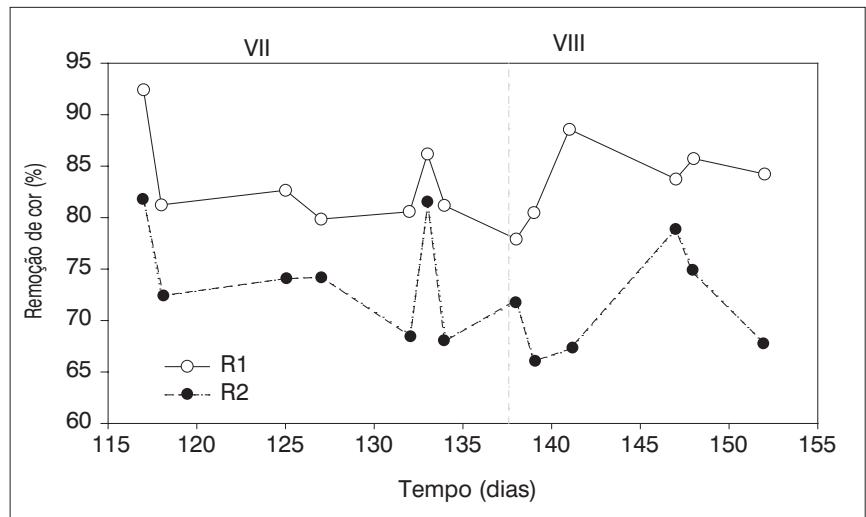

Figura 6 - Eficiência de remoção de cor obtida pelos reatores R1 e R2 na presença de nitrato

remoção do corante azo Reactive Red 141 (100, 150 e 200 mg/L), em um meio suplementado com nitrato nas concentrações de 1, 5 e $10 \mathrm{mM}$. Os autores observaram no experimento uma fase 'lag', a qual aumentava com a concentração de nitrato. Tal fato foi atribuído tanto à melhor preferência do nitrato pelos elétrons gerados nos processos oxidativos comparado ao corante azo, quanto à observação de que quando nitrato era consumido, uma maior taxa de remoção de cor era obtida. Nesse último estudo, a presença de sulfato nas concentrações de 5 e 10 mM não resultou em decaimento das taxas de descoloração.

Panswad e Luangdilok (2000) também encontraram um efeito inibitório do nitrato quanto às taxas de remoção de cor no tratamento de um efluente colorido contendo $20 \mathrm{mg} / \mathrm{L}$ do corante azo Reactive Black 5 em um Reator em Batelada Sequencial (RBS) com glicose como doador de elétrons na concentração de 860 mg/L. Nessa investigação, as concentrações de nitrato testadas foram 5 e $10 \mathrm{mM}$, em que a inibição do processo de remoção de cor era proporcional à concentração testada.

Em oposição às supracitadas pesquisas com nitrato, Pearce et al (2006) não encontraram em experimentos em batelada qualquer inibição ou diminuição das taxas de redução do corante (Remazol Black B na concentração de $50 \mu \mathrm{M}$ ), mesmo tendo utilizado uma concentração mais elevada de nitrato de sódio (20 mM) com formiato como doador de elétrons. Remazol Black B era reduzido preferencialmente, muito embora a concentração de nitrato fosse 800 vezes maior do que a concentração de corante. Portanto, as observações da presente pesquisa estão de acordo com as conclusões desse último trabalho.

Relativo à competição entre redução do corante e outros aceptores de elétrons, a literatura também mostra efeitos contraditórios da presença de sulfato. Cervantes et al (2007) estudaram em experimentos em batelada, o efeito de altas concentrações de sulfato na descoloração redutiva de diferentes corantes azo por lodo anaeróbio. Os autores encontraram pouco ou nenhum efeito do sulfato (5-10 g sulfato/L) nas taxas de descoloração do corante Reactive Orange 14 (RO14), Direct Blue 53 (DB53) e Direct Blue 71 (DB71) na ausência do mediador redox riboflavina. Entretanto, um aumento na concentração de sulfato nas garrafas que continham riboflavina $(20 \mu \mathrm{M})$ proporcionou um aumento na descoloração de todos os corantes em até 3,6 vezes, em comparação aos controles que não possuíam sulfato, mas que continham riboflavina. No decorrer desses experimentos, a redução de sulfato não ocorreu durante a fase de redução do corante, mas somente antes de o corante ser introduzido no sistema e após a redução desse último. Tal observação sugeriu que a redução do corante azo supera a redução do sulfato pelos equivalentes reduzidos disponíveis. Entretanto, outras investigações revelaram um efeito inibitório do sulfato na redução de diferentes corantes (ALBUQUERQUE et al 2005; CERVANTES et al 2006) devido à preferência desse composto como aceptor final de elétrons.

\section{Alcalinidade, AGV e pH no experimento em fluxo contínuo}

Foram realizadas análises de monitoramento do sistema, como $\mathrm{pH}$, alcalinidade e ácidos graxos voláteis, oportunamente ao longo do estudo. A verificação da alcalinidade e ácidos graxos voláteis dos reatores foi iniciada após 50 dias de pesquisa, conforme mostrado na Figura 7.

A alcalinidade total média nos reatores R1 e R2 foi de 1152 e $1530 \mathrm{mgCaCO}_{3} / \mathrm{L}$ para os reatores R1 e R2, respectivamente. Os altos valores encontrados se devem à adição de bicarbonato de sódio ao meio basal, medida que favorecia a segurança do reator para evitar possíveis choques ácidos advindos da degradação do doador de elétrons etanol. Sponza e Isik (2005) trabalharam com valores mais altos ainda e isso não significou problemas em relação à remoção de cor e de DQO. Em outro estudo sobre a relação entre a alcalinidade e a remoção de cor do corante Congo Red em um reator UASB, Isik e Sponza (2005) não encontraram evidências da relação entre alcalinidade e remoção de cor do corante. 


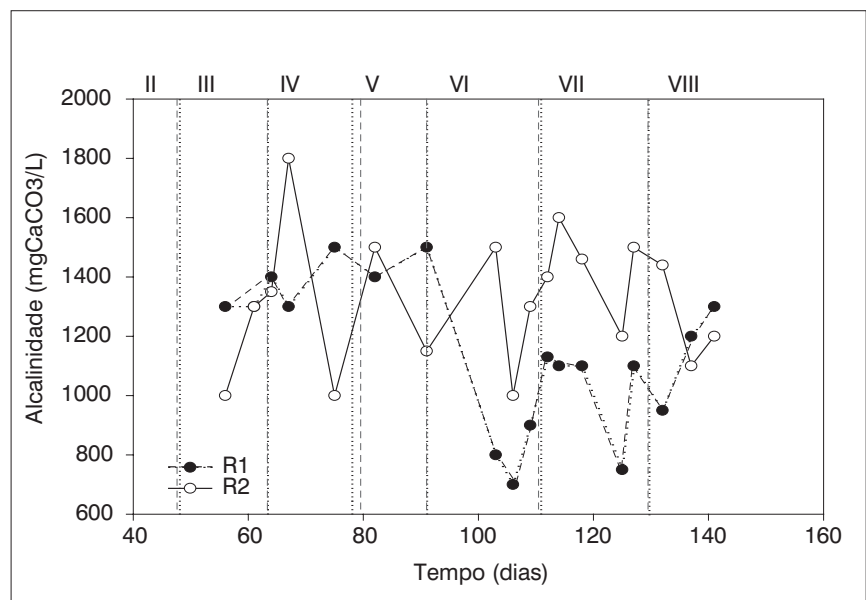

Figura 7 - Alcalinidade presente nos reatores R1 e R2 durante 0 experimento de fluxo contínuo

A variação temporal dos ácidos graxos voláteis do efluente dos reatores R1 e R2 é apresentada na Figura 8, com valores médios de 281 e 359 mgHAc/L, respectivamente. A variação da relação AGV/AT e do pH dos reatores estão dispostos nas Figuras 9 e 10.

A relação AGV/AT teve um valor médio de 0,24 para R1 e 0,28 no R2, apesar de em alguns casos terem sido verificados valores acima de 0,4 , que poderiam ser indício de instabilidade aos reatores (BEHLING et al, 1997). Entretanto, tais variações são frequentes em sistemas biológicos e acredita-se que os reatores anaeróbios tenham se mostrado perfeitamente estáveis.

Os valores médios de $\mathrm{pH}$ foram 7,5 para ambos os reatores, próximos da faixa ótima de $\mathrm{pH}$ de 6,6 e 7,4 para os micro-organismos metanogênicos (CHERNICHARO, 2007). Valores de pH acima de 8 e abaixo de 6 podem inibir por completo micro-organismos formadores de metano (VAN HAANDEL; LETTINGA, 1994). Segundo Pearce, Lloyd e Guthrie (2003), o pH ótimo para remoção de cor é frequentemente um valor neutro ou ligeiramente alcalino e as taxas de remoção de cor tendem a decrescer rapidamente em pHs muito ácidos ou muito alcalinos, sendo necessário sempre que o efluente têxtil seja tamponado para melhorar a eficiência de remoção de cor por culturas celulares.

\section{Efeito de um gradiente de concentração de doador de elétrons nas taxas de remoção de cor}

Foi estudado em batelada o efeito da concentração do doador de elétrons etanol nas taxas de redução do corante azo RR2 testado na concentração de 0,06 mM. O mediador redox AQDS estava presente em algumas garrafas na concentração de $25 \mu \mathrm{M}$, e o doador de elétrons etanol foi testado em várias concentrações.

A remoção de cor do experimento em batelada na presença de lodo e corante azo RR2 seguiu uma reação de primeira ordem em relação à concentração do corante azo. A constante de primeira ordem $\mathrm{k}_{1}\left(\mathrm{dia}^{-1}\right)$ foi determinada através de regressão linear. Na Tabela 5 são

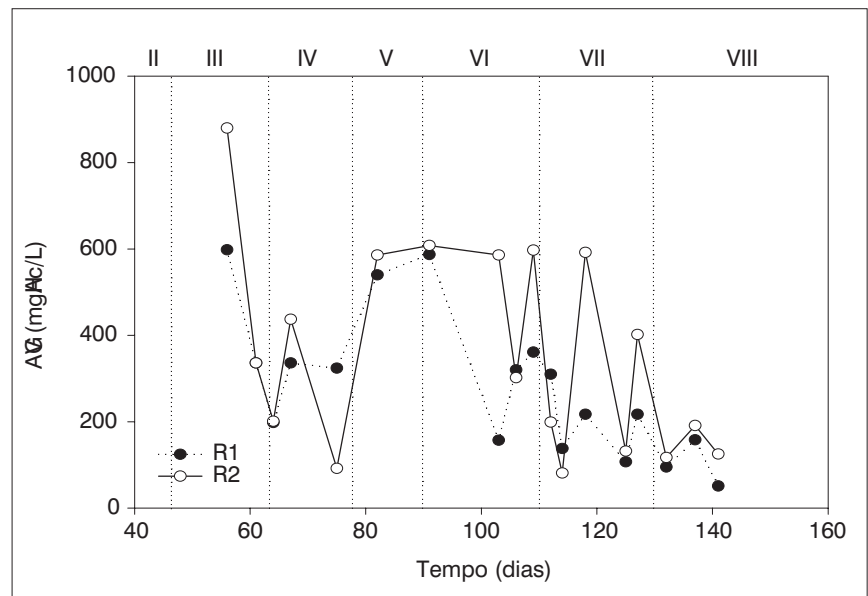

Figura 8 - Ácidos Graxos Voláteis (AGV) nos reatores R1 e R2 durante 0 experimento de fluxo contínuo

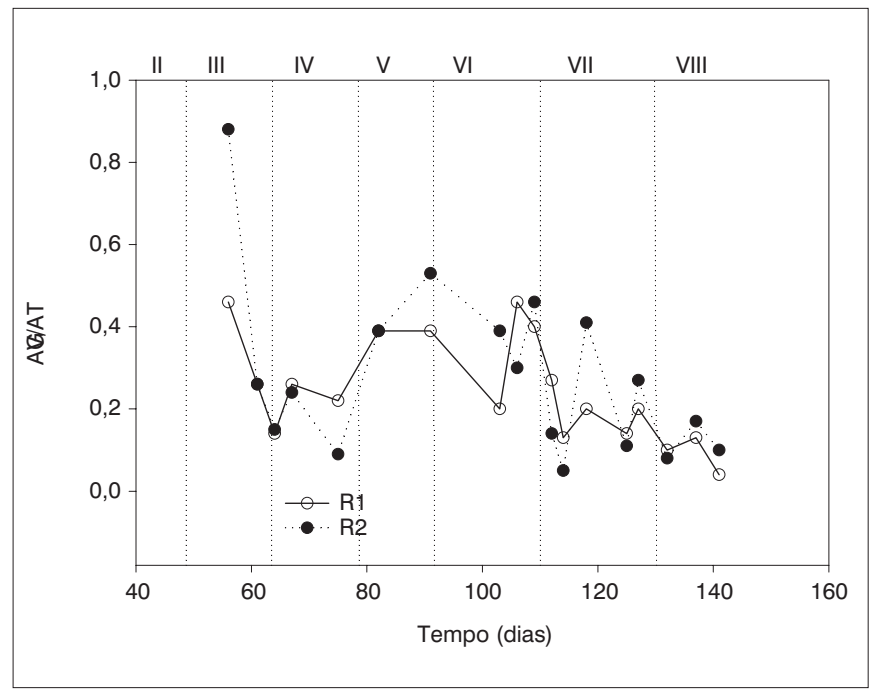

Figura 9 - Razão AGV/AT nos reatores R1 e R2 durante 0 experimento de fluxo contínuo

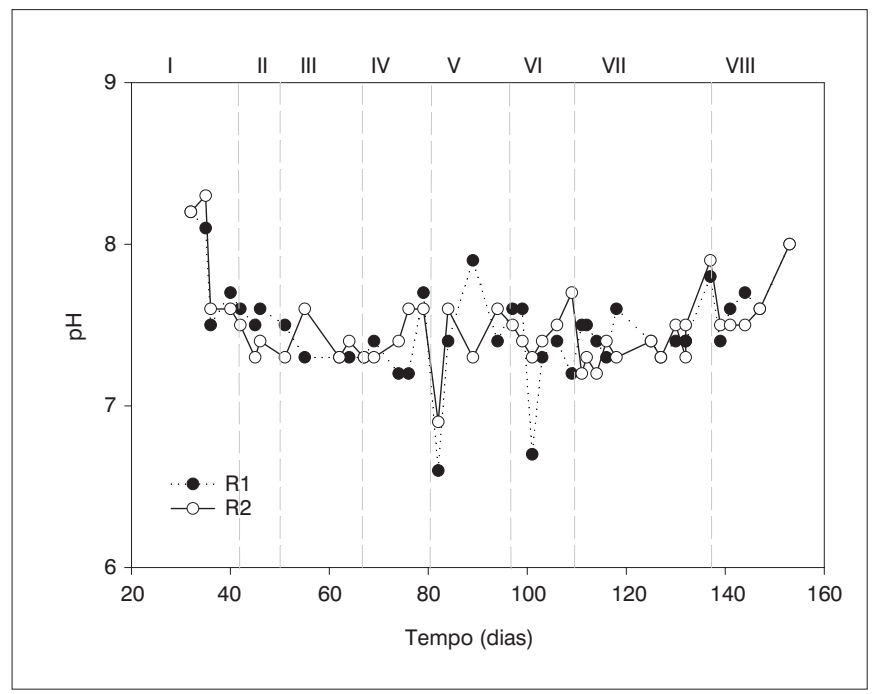

Figura 10 - Valores de $\mathrm{pH}$ do efluente dos reatores R1 e R2 durante 0 experimento em fluxo contínuo 
Tabela 5 - Constante de primeira ordem $\left(k_{1}\right)$ na remoção de cor do corante azo modelo RR2 em lodo granular mesofílico na ausência e presença do mediador redox AQDS com concentrações variadas do doador de elétrons etanol

\begin{tabular}{lc} 
Amostra & k1/SSV $\left(\right.$ dia $\left.^{-1} \mathrm{~g}^{-1} \mathrm{~L}\right)$ \\
$50 \mathrm{mgDQO} / \mathrm{L}$ & $0,187(0,01)$ \\
$100 \mathrm{mgDQO} / \mathrm{L}$ & $0,211(0,02)$ \\
\hline $500 \mathrm{mgDQO} / \mathrm{L}$ & $0,449(0,02)$ \\
$1000 \mathrm{mgDQO} / \mathrm{L}$ & $0,556(0,04)$ \\
\hline $100 \mathrm{mgDQO} / \mathrm{L}+$ AQDS & $0,604(0,01)$ \\
\hline $500 \mathrm{mgDQO} / \mathrm{L}+$ AQDS & $0,943(0,08)$ \\
\hline $1000 \mathrm{mgDQO} / \mathrm{L}+$ AQDS & $1,512(0,03)$ \\
\hline
\end{tabular}

Os resultados são médias de duplicatas, com o desvio padrão indicado entre parênteses.

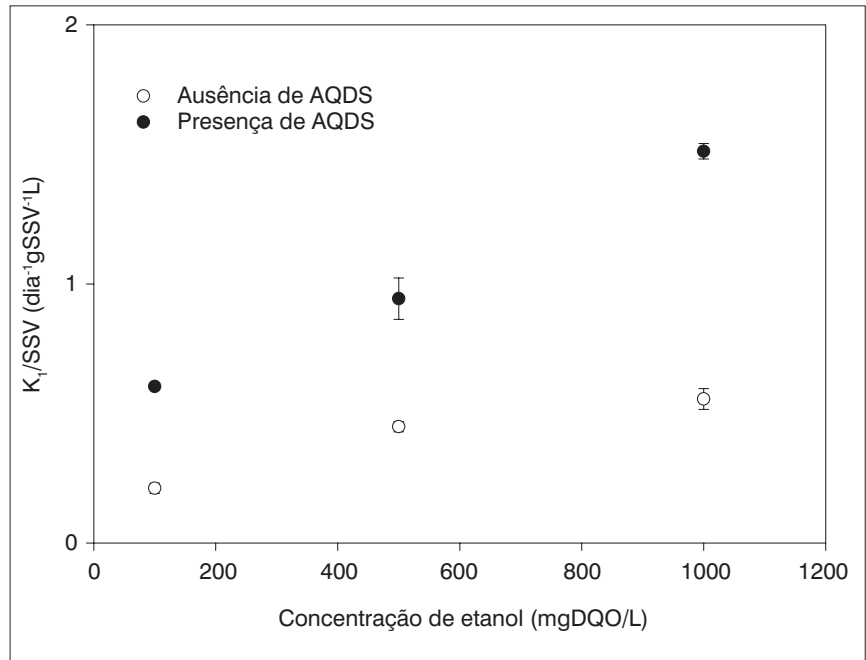

Figura 11 - Redução do RR2 em diferentes concentrações de etanol em incubações livres e suplementadas com AQDS. Os resultados são médias de duplicatas e as barras indicam o desvio padrão

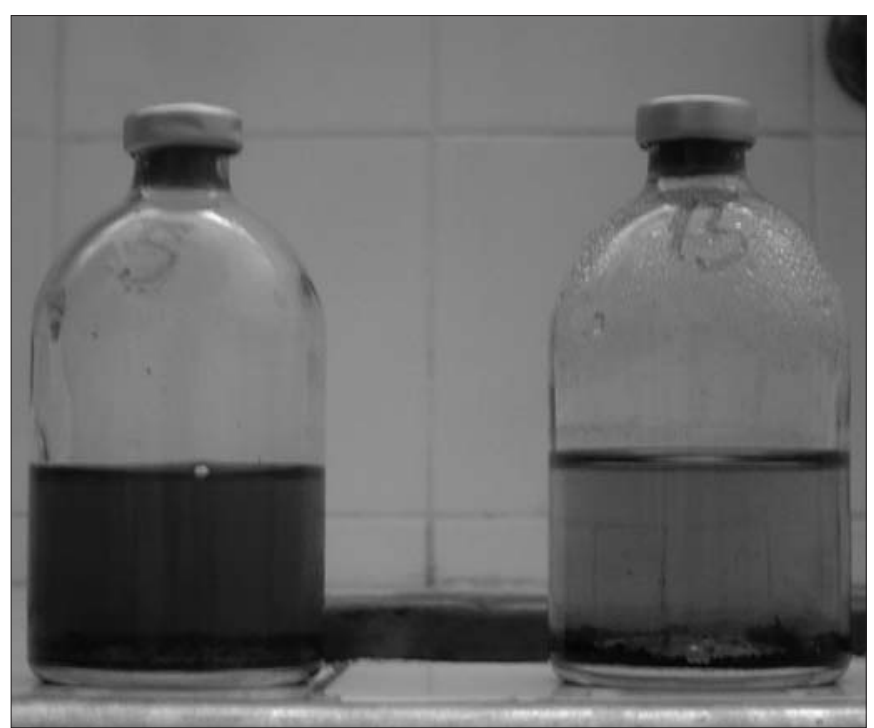

Figura 12 - Coloração do corante RR2 no início do experimento (vermelho) e após a sua redução (amarelo) apresentados os valores calculados de $\mathrm{k}_{1}$ normalizados pela concentração de SSV das garrafas.

As taxas de descoloração foram aumentadas com a inclusão do doador de elétrons etanol e mostraram-se proporcionais à sua concentração. Por exemplo, as taxas de descoloração das garrafas com $1000 \mathrm{mgDQO} / \mathrm{L}$ de etanol foram três vezes maiores do que os valores para uma concentração de $50 \mathrm{mgDQO} / \mathrm{L}$, ambos na ausência de AQDS.

As garrafas que continham AQDS também tiveram desempenho proporcional ao gradiente de concentração do cossubstrato. Por exemplo, as taxas de descoloração das garrafas com 1000 mgDQO/L de etanol foram 2,5 vezes maiores do que os valores para uma concentração de 100 mgDQO/L de etanol.

Pode-se observar, na Figura 11, o impacto do gradiente de concentração do doador de elétrons, bem como o impacto da presença do AQDS, para diferentes concentrações de etanol. Na ausência de lodo granular (controle químico), ocorreu uma remoção de cor insignificante. O valor da relação $\mathrm{k}_{1} / \mathrm{SSV}$ para as garrafas com lodo granular autoclavado (controle abiótico) foi igual a 0,136, valor bem próximo do encontrado para o controle endógeno (garrafas contendo lodo granular, corante e meio basal) igual a 0,123.

Os resultados em batelada mostraram claramente que a redução do corante é principalmente decorrente da contribuição biológica, e que a concentração do doador de elétrons ou DQO é um fator primordial na descoloração de efluentes têxteis contendo corantes azo. Após a completa redução do RR2, as amostras passaram da cor vermelha para amarela, indicando a formação de aminas aromáticas (Figura 12), conforme detectadas em outras pesquisas como as realizadas por Van der Zee, Lettinga e Field (2001) e Dos Santos (2005). Neste último trabalho, detectou-se, em reatores EGSB em fluxo contínuo, a presença da amina aromática anilina, produto esperado da redução do corante azo RR2.

Contrariamente, Isik e Sponza (2005) obtiveram em estudos com o corante Congo Red, taxas de descoloração muito efetivas, em torno de 100\% para concentrações entre 100 e 500 mg/L de glicose, em um reator UASB contendo $100 \mathrm{mg} / \mathrm{L}$ de corante. Mesmo após suprimir a DQO do afluente, eles obtiveram quase 99\% de remoção de cor. Razo-Flores (1997) obteve remoção do corante azo Mordant Orange 1 em torno de 60\%, testado em concentrações de $12 \mathrm{mg} / \mathrm{L}$ por 20 dias, em reatores UASB sem a presença de cossubstrato. Contudo, após elevar a concentração do corante para $75 \mathrm{mg} / \mathrm{L}$, as taxas de remoção caíram para 10\%, ao contrário de outros dois reatores testados. Um dos reatores recebeu glicose na concentração de 1,3 gDQO/L e o outro recebeu uma mistura de AGV na concentração de 1,5 gDQO/L. Ambos os reatores mostraram eficiências de descoloração superiores a 90\%. Segundo o autor, até certo ponto, o substrato endógeno presente no reator pode fornecer os elétrons para reduzir o corante azo, mas que depois houve a necessidade de um cossubstrato como fonte de elétrons. 
$\mathrm{Na}$ presente investigação, o controle endógeno foi 1,8 vez menor do que as garrafas contendo $100 \mathrm{mg} / \mathrm{L}$ de etanol, o que indica que os equivalentes reduzidos gerados pela respiração endógena eram insuficientes para a promoção da redução do corante, provavelmente pela baixa concentração de biomassa do experimento em batelada em comparação ao experimento em fluxo contínuo de Razo-Flores (1997).

O gradiente de concentração do doador de elétrons pode melhorar substancialmente as taxas de redução de cor, como mostram os estudos de O'neil et al (2000) que ao tratarem um efluente contendo 0,75 g/L do corante azo Red H-E7B com duas concentrações diferentes de amido, 1,9 e 3,8 g/L, fizeram aumentar substancialmente a capacidade de descoloração do sistema. Brás et al (2001) constataram um aumento na remoção de cor do corante azo Acid Orange 7 (100 mg/L) ao aumentar a concentração do cossubstrato, glicose e sucrose de 300 até $3000 \mathrm{mgDQO} / \mathrm{L}$, em sistemas com culturas metanogênicas em batelada.

\section{Conclusões}

Com base nos resultados apresentados pode-se concluir que:
- elevadas eficiências de descoloração de corante RR2 foram obtidas nos reatores anaeróbios mesofílicos, sendo o composto etanol um efetivo doador de elétrons;

- o efeito do mediador redox AQDS como catalisador do processo de redução do corante não foi tão marcante, provavelmente devido às baixas concentrações de RR2 testadas;

- contrariamente às hipóteses de que a adição de nitrato poderia diminuir as taxas de remoção de cor e propriedades catalíticas do mediador redox, nenhum efeito foi observado nos bioreatores, sugerindo que a presença de nitrato em efluentes têxteis não diminuirá a capacidade de reatores anaeróbios, suplementados ou não com mediadores redox, em descolorir corantes azo;

- o experimento em batelada mostrou que as taxas de remoção de cor aumentaram com a concentração do doador de elétrons etanol, assim como o impacto do mediador redox AQDS.

\section{Agradecimentos}

Os autores agradecem ao Conselho Nacional de Desenvolvimento Científico e Tecnológico (CNPq) pelo apoio financeiro e pela concessão da bolsa de mestrado.

\section{Referências}

ALBUQUERQUE, M.G.E. et al. Biological sulphate reduction and redox mediator effects on azo dye decolourization in anaerobic-aerobic sequencing batch reactors. Enzyme and Microbial Technology, v. 36, p. 790-799, 2005

APHA. Standard methods for examination of water and wastewater. 20. ed. Washington, DC: American Public Health Association, 2000.

BEHLING, E. et al. Domestic wastewater treatment using a UASB reactor. Bioresearch Technology, v. 61, p. 239-245, 1997.

BRÁS, R. et al. Batch tests for assessing decolourization of azo dyes by methanogenic and mixed cultures. Journal of Biotechnology, v. 89, p. 155-162, 2001.

CARLIELL, C.M. et al. Microbial decolourization of a reactive azo dye under anaerobic conditions. Water S A. v. 21, 1995.

CERVANTES, F.J. et al. Biogenic sulphide plays a major role on the riboflavin-mediated decolourisation of azo dye under sulphate-reducing conditions. Chemosphere, v. 68, p. 1082-1089, 2007.

. The role of sulphate reduction on the reductive decolorization of the azo dye Reactive Orange 14. Water Science and Technology, v. 54, n. 2, p. 171-177, 2006.
. Enhanced decolourization of acid orange 7 in a continuos UASB reactor with quinines as redox mediators. Water and Science Technology, v. 44 , n. 4 , p. 123-128, 2001

CHERNICHARO, C.A.L. Reatores anaeróbios. 2. ed. Belo Horizonte: DESA/UFMG, 2007.

DOS SANTOS, A.B. Reductive decolourisation of dyes by thermophilic anaerobic granular sludge. (PhD Thesis). Sub-department of Environmental Technology, Wageningen: Wageningen University, 2005.

DOS SANTOS, A.B.; CERVANTES, F.J.; VAN LIER, J.B. A review on current technologies for decolourisation of textile wastewaters: perspectives for anaerobic biotechnology. Bioresource Technology, v. 98, p. 2369-2385, 2007.

DOS SANTOS, A.B. et al. Biogenic sulphide plays a major role on the riboflavin-mediated decolourisation of azo dye under sulphate-reducing conditions. Enhancing the eletron transfer capacity and subsequent colour removal in bioreactors by applying thermophilic anaerobic treatment and redox mediators. Biotechnology and Bioengineering, v. 89, p. 42-52, 2005.

Effect of different redox mediators during thermofilic azo dye reduction by anaerobic granular sludge and comparative study between mesophilic $\left(30^{\circ} \mathrm{C}\right)$ and thermofilic $\left(55^{\circ} \mathrm{C}\right)$ treatments for decolourization of textile wastewaters. Chemosphere, v. 55, p. 1149-1157, 2004. 
FIELD, J.A.; BRADY, J. Riboflavin as a redox mediator accelerating the reduction of azo dye Mordant Yellow 10 by anaerobic granular sludge. Water Science and Technology, v. 48, p. 187-193, 2003.

FIELD, J.A. et al. Biogenic sulphide plays a major role on the riboflavin-mediated decolourisation of azo dye under sulphatereducing conditions. Role of quinines in the biodegradation of priority pollutants: a review. Water Science and Technology, v. 42, p. 215-222, 2000

Biogenic sulphide plays a major role on the riboflavin-mediated decolourisation of azo dye under sulphate-reducing conditions. Enhanced biodegradation of aromatic pollutants in cocultures of anaerobic and aerobic bacterial consortia. Antonie van Leeuwenhoek. v. 67, p. $47-77,1995$

ISIK, M.; SPONZA, D.T. Effects of alcalinity and co-substrate on the performance of an upflow anaerobic sludge blanket (UASB) reactor through decolorization of Congo Red azo dye. Bioresource Technology, v. 96, p. 633-643, 2005.

KUDLICH, M.; KECK, A.; STOLZ, A. Localization of the enzyme system involves in anaerobic reduction of azo dyes by Sphingomonas sp. strain BN6 and effect of artificial redox mediators on the rate of azo dye reduction. Applied and Environmental Microbiology, v. 63, p. 3691-3694, 1997.

O'NEIL, C. et al. Anaerobic-aerobic biotreatment of simulated textile effluent containing varied ratios of starch and azo dye. Water Research, v. 34, n. 88 , p. $2355-2361,2000$
PANSWAD, T.; LUANGDILOK, W. Decolorization of reactive dyes with different molecular structures under different environmental conditions. Water Research, v. 34, n. 17, p. 4177-4184, 2000.

PEARCE, C.I. et al. Reactive azo dye reduction by Shewanella strain j18 143. Biotechnology and bioengineering, v. 95, n. 4, p. 692-703, 2006. PEARCE, C.I.; LLOYD, J.R.; GUTHRIE, J.T. The removal of colour from textile wastewater using whole bacterial cells: a review. Dyes and Pigments, v. 58, p. 179-196, 2003.

RAU, J.; KNACKMUSS, H.J.; STOLZ, A. Effects of different quinoid redox mediators on the anaerobic reduction of azo dyes by bacteria. Environmental Science and Technology, v. 36, n.7, p. 1497-1504, 2002.

RAZO-FLORES, E. Biotransformation and biodegradation of N-substituted Aromatics in Methanogenic Granular Sludge. Ph.D Thesis - Wageningen University, Wageningen, The Netherlands, 1997.

SPONZA, D.T.; ISIK, M. toxicity and intermediates of C.I. Direct red 28 dye through sequential anaerobic/aerobic treatment. Process Biochemistry, v. 40, p. $2735-2744,2005$

VAN DER ZEE, F.P.; LETTINGA, G.; FIELD, J.A. Azo dye decolourization by anaerobic granular sludge. Chemosphere, v. 44, p. 1169-1176, 2001.

VAN DER ZEE, F.P.; VILLAVERDE, S. Combined anaerobic-aerobic treatment of azo dyes: a short review of bioreactor studies. Water Research, v. 39, p. 1425-1440, 2005.

VAN HAANDEL, A.C.; LETTINGA, G. Tratamento anaeróbio de esgotos: um manual para regiões de clima quente. Campina Grande: Epgraf, 1994. 